Article

\title{
Analysis and Optimization of Raw Material Supply Chains with regard to Profitability and Sustainability
}

\author{
Sebastian Trojahn ${ }^{1 *}$, Henning Strubelt ${ }^{2}$ \\ 1 Otto von Guericke University Magdeburg; sebastian.trojahn@ovgu.de \\ 2 University of Applied Sciences Bremerhaven; hstrubelt@hs-bremerhaven.de \\ * Correspondence: sebastian.trojahn@ovgu.de
}

\begin{abstract}
Raw material logistics reflects an important aspect of global trade. Raw materials form an essential basis for society, for daily life, and range from apples to zinc. This paper addresses the analysis and optimization of supply chains of raw materials in terms of their economic viability and their sustainability. Type representatives are chosen according to annual transported quantities. Hard coal represents bulk goods, aluminum primary raw materials with medium quantities, and rare earths primary raw materials with small quantities. Their respective supply chains are analyzed and subsequently possible strategies and methods and their application are discussed. The paper shows for the first time that the selection and application of optimization priorities (e.g. profitability or sustainability) depends on the primary raw material and its integration into global production chains.
\end{abstract}

Keywords: raw materials; supply chain; logistics planning; logistics strategies

\section{Motivation for the Optimization of Raw Material Supply Chains}

The dimensions of logistics are a first starting point for the evaluation of a satisfactory logistics service. According to these, logistics is the provision of the right product, in the right quantity, the right quality, to the right place, at the right time, and cost, for the right customer [1], and with the right information. However, the success of the desired logistics process can be extended as required by, for example, compliance with environmental aspects.

Although the entire supply chain should be addressed when optimizing logistics, this work focuses on raw material or natural resources logistics. Natural resources are the basis of a multitude of economic activities. Over the past 30 years, total global material consumption has increased by $80 \%$, and it is projected that by 2050 this consumption will increase to approximately 180 billion tons of different materials [2]. Raw material logistics is to be understood as the provision of raw materials. Consequently, the focus is on the competitive procurement of the required input raw materials for the first step of raw material processing [3]. The aim of this paper is to develop an improved planning procedure by linking logistic methods and concepts in the value chain for individual type representatives of raw materials.

\section{Process Representation and Linkage of Methods for Type Representatives}

Three type representatives - hard coal, aluminum, and rare earths - are selected to demonstrate their different supply chains. In hard coal a raw material with large annual handling volumes is selected, which can also function as an energy raw material for which recycling is not possible. Hard coal represents a classic C-good in the $\mathrm{ABC}$ classification of goods (low value share, consumption can be planned, low capital commitment). The second representative is aluminum and its basic material bauxite. It represents a classic B-good with a medium value share and somewhat more irregular consumption than coal. Moreover, aluminum cannot be used as an energy raw material, but it can be recycled. Rare earths are chosen as the third category of raw materials. Rare earths represent a typical A-good with a very high value share. 


\subsection{Hard Coal}

Hard Coal includes such coals as sub-bituminous to bituminous coals (flame coal, gas flame coal, gas coal, fat coal, forge coal and non-baking coal; in order of increasing proportion of volatiles) and anthracite. However, the exact classification of coal and associated volatiles varies slightly between countries. The principal process sequence for hard coal extraction is shown in Figure 1.

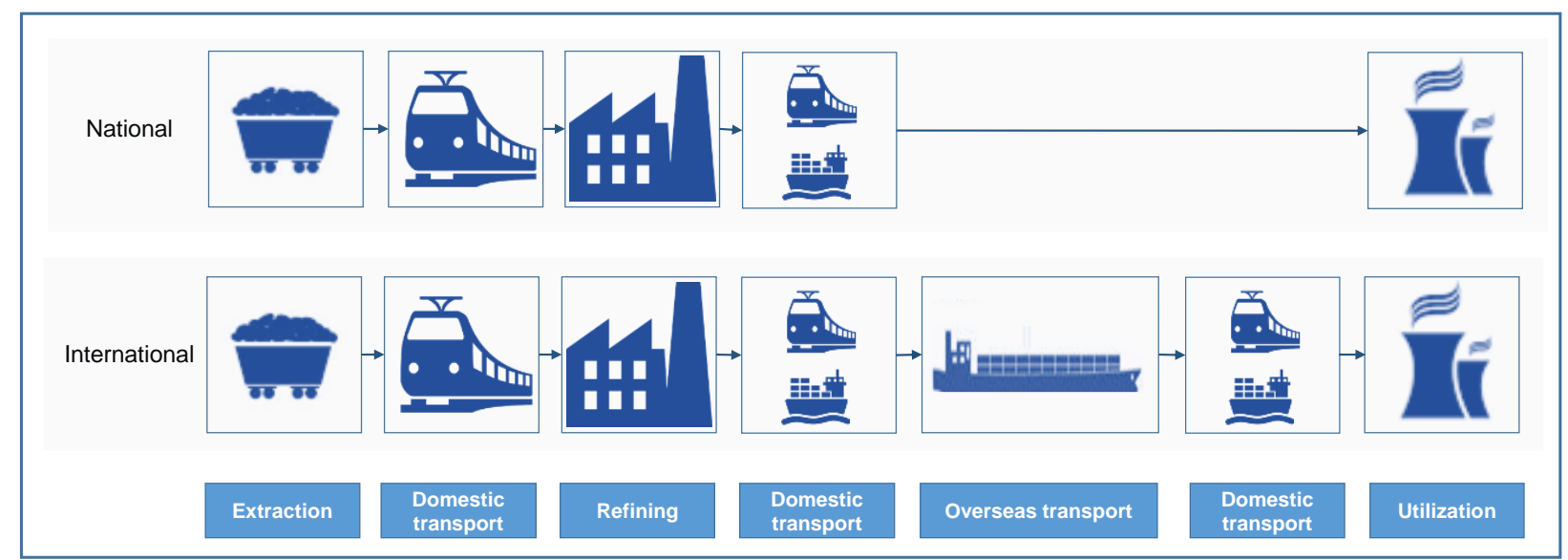

Figure 1. Supply Chain for Hard Coal (based on [4] (pp. 58-61))

The first step is extraction, which can take place either above or below ground. The mined hard coal is usually transported to the processing site on conveyor belts. There, it is freed of impurities, including soil buildup. This is followed by transport for processing. A distinction is made between national and international processing. National transport is here only intended to illustrate the possibilities offered by inland transport [5].

The largest producers of hard coal are Australia, Japan, and China. International transport is generally realized by oversea cargo shipping, while transport from the refining plant to the ports and from the ports to the power stations is mainly carried out either by inland waterway or by rail, depending on the location of the power station.

The characteristics of the logistical properties can be seen in Table 1. Each of the raw materials under consideration is evaluated with regard to its properties, which then influence the selection of appropriate supply chain management methods to optimize the profitability and sustainability of the supply chain. First, the capital commitment costs are considered. Capital commitment costs are costs for the capital invested in the company. In logistics, the costs of capital tied up in inventories play a major role. Capital commitment costs represent opportunity costs for the fact that the capital used for the procurement or production of inventories cannot be used profitably elsewhere. The next properties to consider are the sales volume per year and the demand fluctuations that occur for each raw material. Another point which is included in the evaluation is the suitability for storage or shelf life. This includes how and for how long the raw material can be stored. The property of raw material flexibility illustrates how easy it is to obtain the desired raw materials from another source and by other means of transport. The last characteristic relates to delivery reliability, which is influenced by various aspects of international procurement. 
Table 1. Characteristics of Hard Coal, Aluminum, and Rare Earth Elements (REE)

\begin{tabular}{|c|c|c|c|c|c|}
\hline Characteristic & \multicolumn{5}{|c|}{ Specification } \\
\hline Capital commitment costs & very low & low & medium & high & very high \\
\hline Sales volume per year & very low & low & medium & high & very high \\
\hline Demand fluctuations & very low & low & medium & high & very high \\
\hline Storage suitability & very low & low & medium & high & very high \\
\hline Raw material flexibility & very low & low & medium & high & very high \\
\hline Delivery reliability & very low & low & medium & high & very high \\
\hline & Aluminiu & & & & \\
\hline
\end{tabular}

Based on these properties and market requirements, the following possible supply chain management methods and their options can be discussed: network design, capacity and material requirements planning, procurement, route planning, and forecasting.

The success of a supply chain is based on strategic planning. Network design is that part of planning that considers a time horizon of more than three years in advance. In this step, goals and measures are defined, so as to consolidate the company and achieve the desired growth. Processoriented management strategies are used to optimally plan the network. The best-known representatives are used to apply a strategy selection for the raw materials.

Planning processes, such as capacity planning and subsequent material requirements planning, take place well in advance and can cover time horizons from one week to 24 months. The task of capacity planning is to plan and coordinate the sequence of events based on material requirements. The personnel required, the machines used, and their set-up times must be taken into account. Based on the forecasted customer requirements, material requirements planning serves to secure the material supply for a production site. Here, attempts are made both to prevent material undersupplies, which lead to a loss or stoppage of production, as well as material oversupplies, which lead to increased storage costs.

Procurement combines the supply of a company with materials, services, operating and working materials as well as rights and information from external markets. Procurement can be divided into operational, i.e. short-term activities and strategic procurement, which deals with long-term goals. These include cost minimization, quality assurance, optimization of safety stocks and environmental aspects.

Another important point in logistics that a company must consider is route planning. To keep transport costs as low as possible, it is necessary to make well-founded decisions regarding capacity utilization and the route. These decisions are based on various cost factors, which are divided into fixed and variable costs. Fixed costs in the area of vehicles include their purchase and the associated depreciation, vehicle equipment, and maintenance payments, such as taxes and insurance. In addition to the costs for the vehicles, salaries are incurred for drivers and dispatchers. Variable costs include fuel, spare parts, and any repair costs incurred. On the staff side, there are also possible overtime payments. In contrast with the fixed costs, which are calculated per year, variable costs are calculated based on the distance travelled.

Forecasting procedures are used not only in requirements and capacity planning but also in strategy and personnel planning. Basically, there are two different forecasting methods, the quantitative and the qualitative method. The classical quantitative forecasting method is calculated using mathematical and statistical models, using both historical and quantitative data. It is assumed that the observed trends will continue in the future. However, the increase in dynamics and the 
complexity of environmental conditions create essential disadvantages in quantitative forecasting methods.

Based on the logistics characteristics of hard coal the following methods and concepts can be proposed for the optimization of the profitability and sustainability of the according supply chain of this resource (cf. Table 2).

Table 2. Selection of Logistics Strategies and Methods for the Three Type Representatives

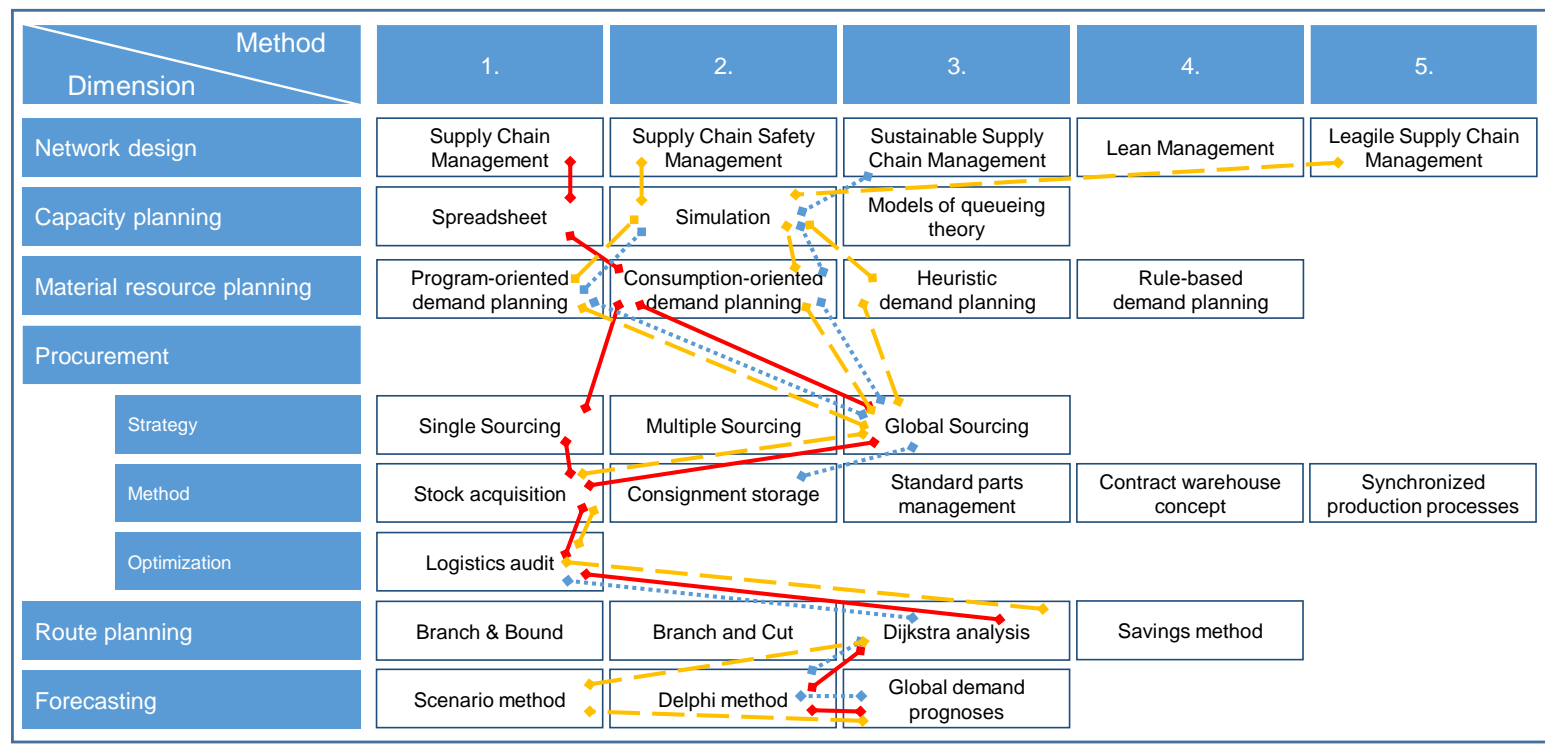
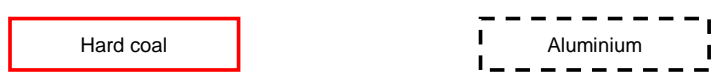

Network design using supply chain management in its pure form is recommended. Even if stock procurement is an important aspect, it is secured by the quickly reachable stocks. Therefore, this aspect does not have to be specifically integrated into the strategy.

The simplest form is sufficient for capacity planning, since the fluctuations in demand are low and the process steps are relatively straightforward. The simplest method is the spreadsheet, where the data is read out in tabular form.

For material requirements planning, consumption-based material requirements planning is the preferred form. The requirements can be simply derived from historical values and calculated using the moving average, for example. In the future, however, coal demand could fall sharply due to the use of substitutes. Only when or if this case occurs, different calculation principles must be used.

As can be seen from the morphological box (cf. Table 2), the next dimension, the procurement strategy, offers two possibilities. To compensate for a possible delivery bottleneck, several suppliers from all over the world are used.

After the supplier selection has been made, the procurement model must be examined in more detail. Even if the requirements can be estimated well, there is no exact cycle time in production, which excludes a JIT delivery. This procurement strategy and the model must be reviewed at regular intervals. However, the dimension optimization does not mean checking the strategy and methods, but the logistics audit ensures that the suppliers are checked at defined intervals.

Route and tour planning is very limited due to the volumes transported. Therefore, it is recommended to use the "shortest path" method for the calculation.

\subsection{Aluminum}


The second type representative investigated is aluminum, chosen to represent raw materials in medium quantities. The material flow shown in the upper section of Fig. 2 refers to primary aluminum, while the lower section refers to secondary aluminum.

For primary aluminum, in the first step, the ore obtained is freed of impurities. The purified bauxite now available is subsequently traded worldwide. For this purpose, it is transported to the next processing step, where each of the previously presented means of transport can be used. Following this processing step, the processed goods are transported by truck or freight train to the nearest port and from there shipped all over the world [6] (pp. 203-219). The bauxite is transported from the port of arrival to the next processing stage. In this step, aluminum oxide, also known as alumina, is produced from bauxite using the Bayer process. To extract one ton of primary aluminum, approximately four to five tons of bauxite or two tons of alumina are required [7]. Thus, it is cheaper, in terms of transport costs, to transport alumina, as much smaller quantities have to be transported. The aluminum obtained can be shaped in various ways, such as ingots, sheets or strips. These are then further processed by subsequent production steps and finally formed into the end product.

The second material flow shown in Figure 2 deals with secondary aluminum. The various types of scrap must first be differentiated into new and old scrap. New scrap is scrap produced in the individual production steps, while old scrap is already used aluminum. The collected aluminum is then sold to the secondary aluminum smelters, where it is re-smelted and then returned to the aluminum cycle [8]. The characteristics of primary and secondary aluminum are shown in Table 1.

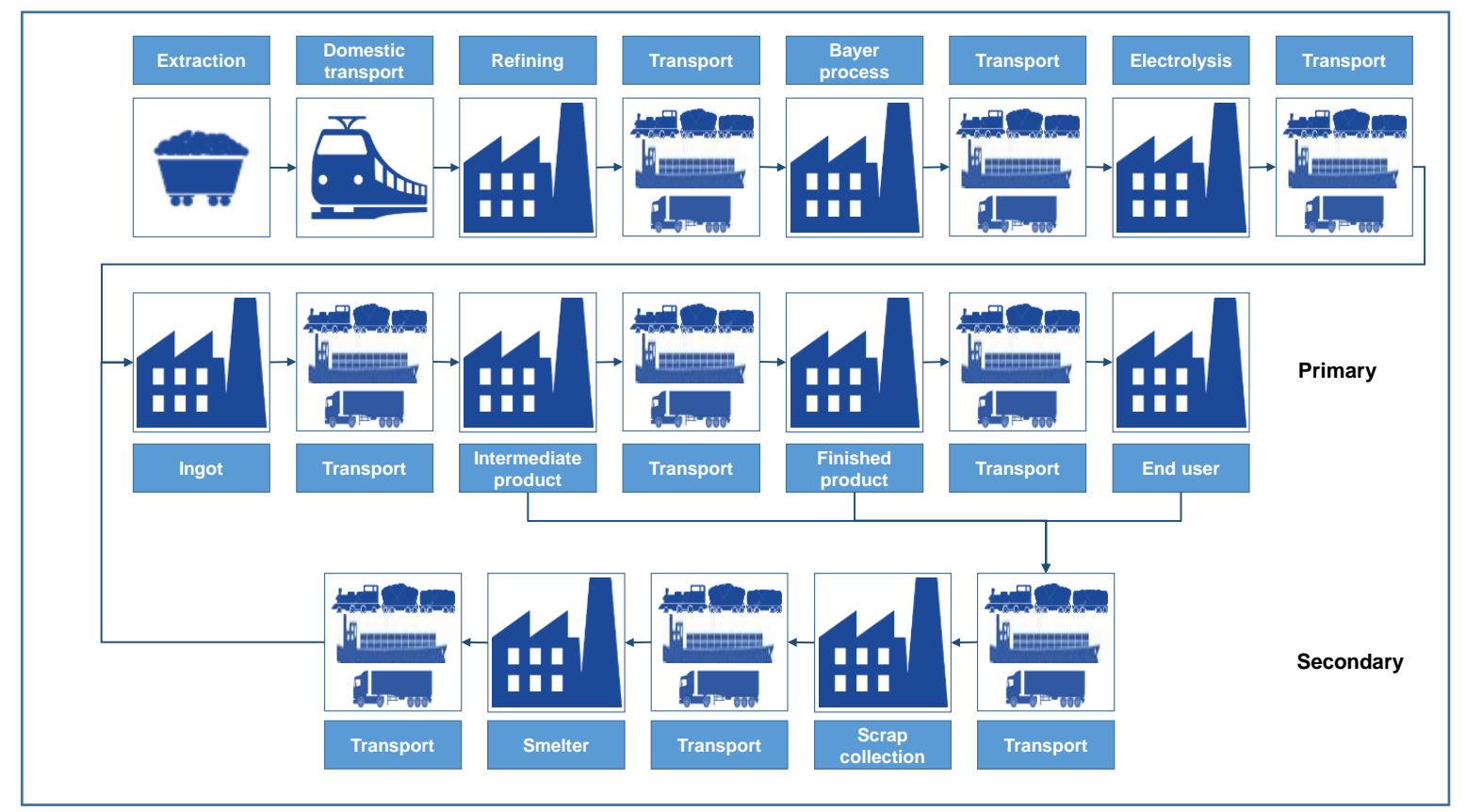

Figure 2. Supply Chain for Primary and Secondary Aluminum (cf. [9])

The sales volume of aluminum is high, because the material is used frequently in industrial production, for example, in body construction. Fluctuations in demand can be classified as low, as consumption is easily estimated and aluminum has established itself as a valuable material in existing supply chains. Its storage suitability is high, but the material can corrode after a certain time. This does not lead to damage, but to possible discolorations and thus to certain quality losses.

Among the procurement models, the consignment warehouse is particularly suitable for aluminum. This means that there are initially no capital commitment costs. The reason for this is the claim of ownership, which only passes to the customer when a material is withdrawn. However, unlike a contract warehouse, the owner of the warehouse is the customer company and there are no expensive contract costs (cf. Table 2). 


\subsection{Rare Earths}

Rare earths is a collective term for rare earth elements (REE) and contains seventeen chemical elements with similar behavioral properties. Due to their geochemical characteristics, rare earths are typically scattered and not often concentrated as rare earth minerals in economically viable ore deposits. The following Figure 3 shows the general process chain for rare earths.

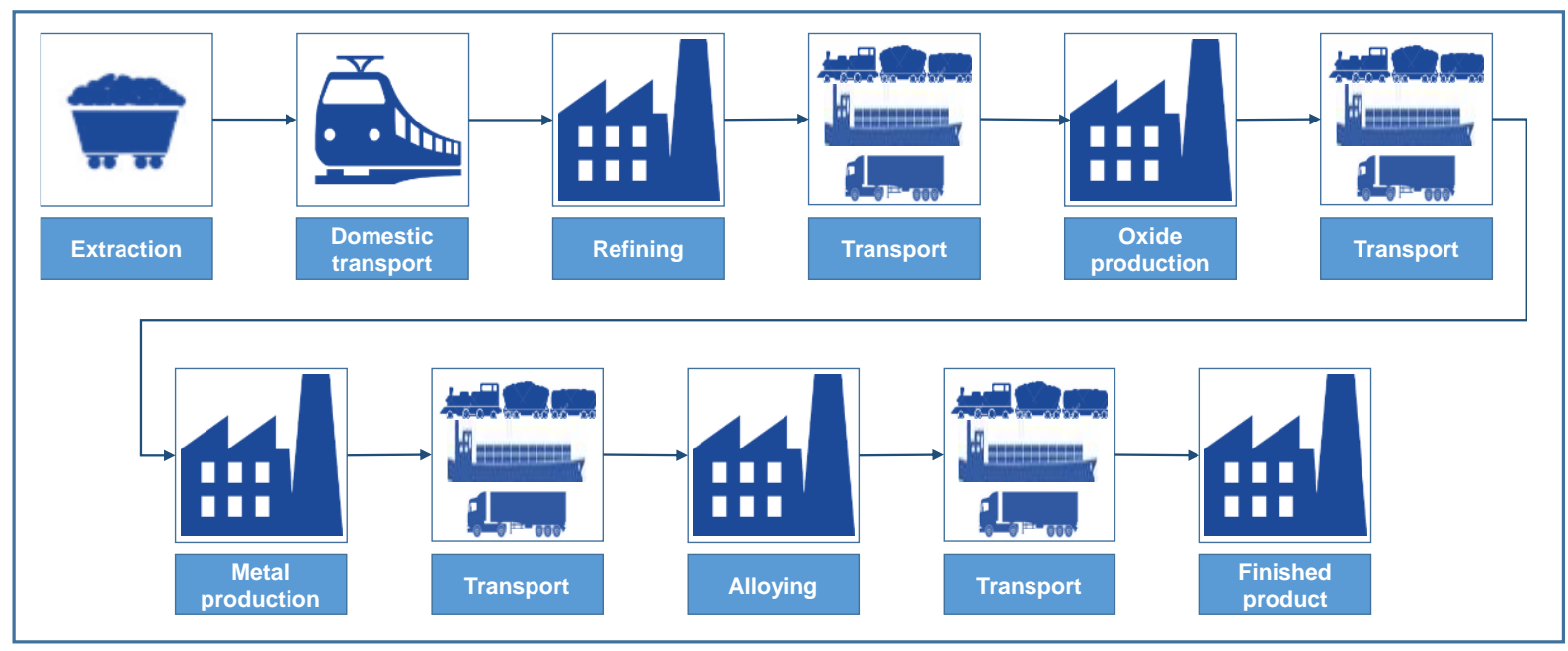

Figure 3. Supply Chain for Rare Earths (based on [10])

At the beginning of the process, the corresponding mineral layer is mined. The oxides are transported either at inland or abroad for further processing [10].

Using the production of a neodymium magnet as an example, the first three steps recovery and concentration, separation into oxides and refining of the oxides into metals, are carried out mainly in China. The metals are then further processed in alloys.

Due to China's dominance of the REE market, most of the steps are carried out in China. Only the last few steps up to the final product take place outside China. The current development of new mines has led to an increase in processing in other countries. The most serious problem here is that the extraction of minerals from the rock is associated with considerable environmental risks. Due to these risks, processing is extremely costly in many countries, as environmental protection regulations must be observed. The characteristic values of rare earths are summarized in Table 1.

REE are only traded in small quantities, but these raw materials are very expensive, leading to extremely high capital commitment costs even for smaller quantities. The sales volume is therefore classified as medium. In the case of a strongly expanding alternative energy production and more frequent use of IT technologies, the demand for REE will continue to increase. The shelf life is good, as the rare earths are in powder form and can therefore be stored in barrels to protect them from environmental influences. As the main reserves and the first processing steps are carried out in China, the flexibility in terms of supplier selection is low. Delivery reliability was also classified as medium as China has already at times exploited its monopoly position and reduced exports and that no other major production sites are yet in operation.

The focus of rare earths should therefore be ensuring the security of supply, applying supply chain safety management. Due to the guarantee of flexibility and the safety aspect, the capacity conditions should be represented by means of a simulation. With this, future scenarios can also be considered.

With the strategies, however, there is only the possibility of global sourcing (cf. Table 2), since not only the extraction, but so far, every intermediate production stage takes place in China. Even if the market today does not have many suppliers for REE, there is the possibility that production facilities will open outside China. 


\section{Conclusions}

This paper discusses existing logistics strategies and methods to enable an optimization in raw material logistics over different dimensions. This discussion of supply chain management strategies is carried out using three raw materials (hard coal, aluminum, rare earths) defined in advance as type representatives.

It was made clear that companies are encouraged to regularly carry out analyses and reevaluate applied methods to continuously optimize their logistics processes. The value-added processes within raw material logistics are constantly changing (also due to political and price influences).

The bulk goods were represented by hard coal. High supply quantities, the integration of hard coal into many production and energy value-added chains bring a good planning security with regard to the necessary quantities. This makes it clear that supply chain management methods should be used for these kind of goods. The raw material aluminum, which represents processing goods with medium mining and transport volumes, is also distinguished by the fact that recycling processes play an important role. The aluminum industry will continue to grow as this raw material is used in many technological areas. In addition, emerging economies are adapting to a more resource-intensive lifestyle and the world's general population is growing. The REE represented the product to be refined with a lower quantity of mined material. Due to the low number of mines, the high price and the political explosiveness, it is not necessary to optimize costs within the logistics chain for rare earths, instead, supply chain safety management methods should be used.

This paper provides an overview of all important methods in the field of supply chain optimization and examines their applicability to different raw materials. By means of example paths over the important dimensions, factors a company must consider in raw material logistics can be identified.

Optimization of the process chain has not yet been treated as a priority, as raw materials themselves are also used for speculative purposes and the income side is thus influenced. Savings on the expenditure side (logistics) have only recently come into the spotlight.

The assignment of applicable logistics methods to resource properties is addressed for the first time in this paper. Not every logistics method brings added value within raw material supply chains. For example, lean concepts for global supply chains are used in manufacturing companies. However, transferring lean methods to the procurement of rare earths does not make sense. This insight into the applicability of logistics methods is a central result of this paper. Furthermore, a suitable selection of logistics methods based on the properties of primary raw materials can be generated from this paper for various applications.

Author Contributions: “Conceptualization, S.T. and H.S.; methodology, S.T.; validation, S.T.; formal analysis, S.T. and H.S.; investigation, S.T.; writing - original draft preparation, S.T. and H.S.; writing - review and editing, S.T. and H.S.; visualization, S.T.. All authors have read and agreed to the published version of the manuscript.".

Funding: "This research received no external funding"

Conflicts of Interest: “The authors declare no conflict of interest."

\section{References}

1. Seven "Rights" of Logistics, in: Swamidass, P.M. (Eds.), Encyclopedia of Production and Manufacturing Management, Springer, Boston, MA, 2000, https://doi.org/10.1007/1-4020-0612-8_871.

2. Dittrich, M.; Giljum, S.; Lutter, S.; Polzin, C. Green economies around the world? Implications of resource use for development and the environment, Sustainable Europe Research Institute (SERI), Vienna, 2012, available online: http://alt.seri.at/wp-content/uploads/2012/06/green_economies around the world.pdf (accessed Oct 30, 2019).

3. Fahimnia, B.; Ebrahimi, M.H.; Molaei, R. Complex Real-Life Supply Chain Planning Problems. In Supply Chain Sustainability and Raw Material Management: Concepts and Processes, Faranhi, R.Z., Rezapour, S., Kardar 
L. (Eds.), Business Science Reference (IGI Global): Hershey, 2012, pp. 102-127, DOI: 10.4018/978-1-61350504-5.ch007.

4. Lambertz, J.; Schiffer, H.-W.; Thielemann, T.; Voß, M. Carbon Footprints fossiler Energieträger in der Stromerzeugung. Energiewirtschaftliche Tagesfragen, Zeitschrift fuer Energiewirtschaft Recht Technik und Umwelt 2012, Volume 62, No. 1/2, pp. 58-61..

5. Wang, J.; Zhang, J.; Li, J. A Scheduling Model of Coal Supply Chain Based on Supply Chain Management (SCM). American Journal of Industrial Engineering 2014, 2(1), pp. 15-20, DOI: 10.12691/ajie-2-1-4.

6. Knierzinger, J. Bauxit und Aluminium aus Afrika: Ausbeutung auf Umwegen. In Globale Ressourcen und Rohstoffpolitik, Aktuelle Auseinandersetzungen im historischen Kontext, Historische Sozialkunde/Internationale Entwicklung, 35th ed.; Fischer, K., Jäger, J., Schmidt, L. (Eds.), New Academic Press: Vienna, 2016, pp. $203-$ 219.

7. Kammer, C. Aluminium Taschenbuch 1 Grundlagen und Werkstoffe, Beuth Verlag: Berlin, 2011.

8. Haraldsson, J.; Johansson, M. Energy Efficiency in the Supply Chains of the Aluminium Industry: The Cases of Five Products Made in Sweden. Energies 2019, 12(2):245, pp. 1-25, https://doi.org/10.3390/en12020245.

9. Trojahn, S.; Strubelt, H. Developing an evaluation methodology for determining the provision energy effort of primary resources using energy value stream mapping. Transportation Research Procedia 2017, 25, Elsevier: Amsterdam, pp. 3578-3589, https://doi.org/10.1016/j.trpro.2017.05.298.

10. Rüttinger, L.; Treimer, R.; Tiess, G.; Griestop, L.; Schüler, F.; Wittrock, J. Fallstudie zu den Umwelt - und Sozialauswirkungen der Gewinnung Seltener Erden in Bayan Obo, China. Adelphi, Berlin, 2014, available online:

https://www.umweltbundesamt.de/sites/default/files/medien/378/dokumente/umsoress fallstudie_selten e_erden_china_bayan_obo.pdf (accessed on Oct. 26, 2019). 